\section{$\underset{\substack{\text { hommes } \\ \text { \& migrations }}}{ }$}

\section{Hommes \& migrations}

Revue française de référence sur les dynamiques

migratoires

$1277 \mid 2009$

France - Allemagne

\title{
La figure de Zidane et le sentiment d'appartenance communautaire des deux côtés du Rhin
}

\section{Nikola Tietze}

Traducteur : Françoise Toraille

\section{OpenEdition}

\section{Journals}

\section{Édition électronique}

URL : http://journals.openedition.org/hommesmigrations/169

DOI : 10.4000/hommesmigrations. 169

ISSN : 2262-3353

\section{Éditeur}

Musée national de l'histoire de l'immigration

Édition imprimée

Date de publication : 1 janvier 2009

Pagination : 94-96

ISSN : 1142-852X

Référence électronique

Nikola Tietze, «La figure de Zidane et le sentiment d'appartenance communautaire des deux côtés du Rhin », Hommes \& migrations [En ligne], 1277 | 2009, mis en ligne le 29 mai 2013, consulté le 19 avril 2019. URL : http://journals.openedition.org/hommesmigrations/169 ; DOI : 10.4000/ hommesmigrations.169 


\title{
La figure de Zidane et le sentiment d'appartenance communautaire des deux côtés du Rhin
}

\author{
Par Nikola Tietze, \\ assistante à l'Institut de recherche sociale de Hambourg et chercheur associée \\ au Centre d'analyse et d'intervention sociologique (Cadis)
}

En tant que figure emblématique de la grandeur du football, Zinedine Zidane permet d'établir une approche sociologique de la construction d'un sentiment d'appartenance sub et transnational. C'est ce qui se dégage de déclarations faites à Berlin, à Hambourg, à Paris et à Lyon par des musulmans, des Kabyles et des Palestiniens. Ces personnes ont été interviewées sur la manière dont elles conçoivent la communauté comme bien commun dans son opposition critique au contexte social et politique. Autrement dit, le personnage de Zinedine Zidane permet de souligner combien la construction du sentiment d'appartenance dépasse, chez les descendants des immigrants des années 1960, les frontières ethniques et l'affirmation identitaire.

En écho aux multiples portraits de la star du football à travers la presse, la publicité, la littérature et l'art, une diversité analogue se manifeste dans la manière dont les personnes interrogées justifient leur sentiment communautaire, quand elles s'expriment à propos de Zinedine Zidane. Indépendamment des dogmes de l'islam, d'éléments de culture kabyle ou du nationalisme palestinien, six principes distincts permettent de légitimer l'appartenance à une communauté : le génie commun, les racines, la solidarité, la réussite, le respect et la nature physique. Chacun de ces termes précise ce que doivent être de bonnes relations sociales, mais aborde également une situation existante qu'il convient de critiquer.

\section{L'artiste génial ou l'exemple du bon père kabyle}

Les qualités exceptionnelles de Zinedine Zidane apportent, selon certains des musulmans, Kabyles ou Palestiniens interrogés, la preuve que leurs diverses communautés sont valorisées par la perfection et par une force créatrice inspirée. 
Ici, c'est le génie qui constitue le principe central qui permet de mettre le sentiment d'appartenance à distance des conditions sociales existantes. Une telle représentation donne naissance à des modèles sociaux contrastant avec la société existante et avec son ordre politique imparfait. Zidane joue alors le rôle d'un artiste d'exception dont le jeu dépasse le cadre du football français. Il est au service du monde entier et marque des buts au nom de l'art.

Face à cette perception, la conception de la communauté se modifie dès lors qu'est associée au joueur de foot la fidélité à l'épouse, aux enfants, au père et à la mère. Ici, ce sont les racines qui constituent le fondement de communautés imaginaires; les traditions immuables tissent un lien de continuité et établissent de bonnes pratiques sociales. L'autorité et la notion de hiérarchie sont les bases de systèmes de valeurs autoritaires de ce type ; elles cherchent à expliquer la société à l'aide de l'ordre familial. Zidane apparaît dans ce cas comme le Kabyle ou le père de famille aux deux pieds sur terre, qui se soumet à l'intérêt national français. Quand les personnes interrogées soulignent l'esprit d'équipe du sportif, elles légitiment les liens communautaires par le principe de solidarité. Leur vision se construit contre l'individualisme ou le pluralisme, ou contre un idéal de la performance répondant à la loi du marché qui célèbre les joueurs en tant qu'individus isolés. Selon ces témoignages, Zidane marque des buts, ou fait don de son argent, exclusivement pour servir les intérêts des Kabyles ou des musulmans. Si en revanche les personnes interviewées placent au premier plan les efforts faits par Zidane et son entraînement pendant des années, les liens existants se trouvent justifiés par le principe de la performance. Dans ce cas, les efforts et les peines endurées sont des éléments constitutifs de la communauté. Les mérites de celle-ci, contrastant avec le mépris qu'elle subit et avec une répartition injuste des biens sociaux, cimentent leur sentiment d'appartenance. Zidane est alors le fils d'immigrants de banlieue qui a réussi à s'élever dans l'échelle sociale, en travaillant dur et avec application.

\section{La star de la différence : un nom et une tête d'Arabe}

Pour d'autres encore, Zidane représente avant tout la différence. C'est une figure qui oblige à respecter les particularismes et la liberté. Reconnaître ces deux normes, telle est alors la revendication fondatrice de la communauté, en opposition à l'hégémonie politique et culturelle de la majorité. Dans ces constructions de l'appartenance, la star du foot est désignée par les noms qui soulignent son altérité, Zinedine ou Yasid, et le surnom Zizou, sous lequel on connaît le héros 
national, est l'objet de critiques. Enfin, quand l'aspect physique prend une place centrale dans les récits portant sur les traits communs, la communauté se caractérise par les stigmates qui la marquent et par les conditions sociales dominantes dont elle est victime. Les spécificités physiologiques des individus déterminent alors leur appartenance à la collectivité imaginée. C'est une tête d'Arabe qui marque des buts pour la France.

Traduction de Françoise Toraille 